\title{
TAMANCÓFILOS E TAMANCÓFOBOS \\ DE 1925
}

Luís Bueno*

$\mathrm{N}$

o dia 21 de abril de 1924, o jornalista Antônio Torres (1885-1934) fez uma conferência em homenagem a Tiradentes no Centro Mineiro do Rio de Janeiro. Um ano depois, a pequena conferência aparecia impressa, com o título de As razões da Inconfidência, precedida por preâmbulo de mais de 100 páginas e acrescida de extensas notas. O espantoso é que a primeira edição, de três mil exemplares, esgotou-se em apenas 15 dias. A segunda tiragem também não esquentou lugar nas prateleiras, de tal forma que no final de julho uma nova edição, a terceira, chegava ao mercado, com um prefácio cheio de orgulho pela popularidade da obra:

Tenho honra e prazer em comunicar aos meus inúmeros admiradores mourejantes no jornalismo tamancófilo da minha pátria infeliz - que esta é a terceira edição do presente livro.

Quisera dizer deste livro redentor. Não no digo, por saber ser impossível redimir o irredimível. O caso do Brasil em relação à

* Universidade Federal do Paraná. 
mentalidade portuguesa não se pode diluir em vagas teorias sociológicas. O Brasil é um simples mas enorme caso de eugenia e de saúde pública. Melhor dizendo: o Brasil, enquanto for português (como desgraçadamente é), nunca será uma nação. ${ }^{1}$

Não é difícil perceber, mesmo a partir de um trecho pequeno como este, que as razões do sucesso do livro não têm relação propriamente com a Inconfidência Mineira, em princípio seu tema central. O que garantiu o público para As razões da Inconfidência foi seu radical e irracional antilusitanismo - sua tamancofobia, para ficar nos termos do próprio Antônio Torres. No início do século XX temos no Brasil campo fértil para essa recusa ao português - que, no limite, é uma espécie de recusa de nossas próprias origens. O Brasil se modernizava. O Rio de Janeiro se remodelava, adequando-se ao papel de grande metrópole mundial plantada em plena América do Sul. A industrialização crescia. Às elites não agradava mais a figura de grande país agrário. Enfim, o novo Brasil que surgia negava o velho país herdado da colonização portuguesa.

O centenário da Independência, comemorado com barulho, confirmaria e aprofundaria esse sentimento. Era como se uma nova independência, agora verdadeira, fosse proclamada. Embora o presidente português participasse dessas comemorações, e o presidente brasileiro, Epitácio Pessoa, em seu discurso, afirmasse que o centenário era uma festa ao mesmo tempo portuguesa e brasileira, pipocavam grupos que defendiam um nacionalismo estreito, excludente. Esse é o caso, por exemplo, da Ação Social Nacionalista, que contava com o apoio do próprio Epitácio Pessoa.

É certo também que, por outro lado, havia espíritos imunes a esse sentimento geral, que nutriam grande respeito pela obra de colonização empreendida pelos portugueses no Brasil. Foram esses espíritos que promoveram verdadeira campanha contra Antônio Torres, criando uma polêmica que, como era de se esperar, só aumentou a curiosidade geral, ajudando a fazer propaganda do livro.

Dezenas de artigos de jornal e alguns livros foram publicados em resposta a As razões da Inconfidência. Um desses livros se chamava mesmo As razões da maledicência e fazia troça com a capa do livro de Antônio Torres, que copiava o padrão dos livros do século XVIII, trazendo a grafia razoens e informações tais

1 TORRES, A. As razões da Inconfidência. 3. ed. Rio de Janeiro: Castilho, 1925. p. ix. Daqui para a frente aparecerá apenas, entre parênteses, a página desta edição de onde forem tiradas as citações. 
como a de que seu autor era "escriptor publico morador em esta muy leal e heroyca cidade de Sam Sebastiam do Rio de Janeiro".

Mas a mais conseqüente dessas respostas é um livro do também jornalista Vitório de Castro, Brasileiros e portugueses, escrito e publicado com uma agilidade invejável ainda para os padrões de hoje, já que seu lançamento se fez no final de maio de 1925, apenas um mês depois da publicação de As razões da Inconfidência.

O livro de Antônio Torres na verdade são dois. Um, a conferência em si que, embora inspirada por um espírito antilusitano, tem aspirações por assim dizer científicas que levam o autor a pelo menos circunscrever sua repulsa ao português aos limites que o assunto lhe permite. O outro é o longo preâmbulo, cujo tom é bem aquele do trecho de abertura citado. Aqui não há limites para o antilusitanismo, que deixa de lado qualquer pretensão ensaística e se confunde com a mera piada de português.

Nesse preâmbulo, todos os problemas do Brasil são culpa da colonização portuguesa. No presente, Portugal aparece como uma nação ridícula na Europa e o Brasil como uma nação atrasada. $\mathrm{O}$ ataque baixa a detalhes, de forma que nem mesmo a aventura aeronáutica de Sacadura Cabral merece crédito. Como uma espécie de cavaleiro sagrado por si mesmo, nesse texto Antônio Torres se vê nada menos do que na posição daquele que traz a verdade. É a isso que ele atribui o sucesso que a conferência obtivera: "O que fez vibrar o meu auditório foi o esplendor da verdade" (p. xxix), diz ele. Trata-se, evidentemente de uma verdade sabida por todos, mas que apenas ele reuniu todas as condições necessárias para dizer:

Eu disse o que todos pensam, mas ninguém tem coragem, ou oportunidade para dizer. Documentei a opinião geral, ordinariamente confusa. Clamei a evidência. Poderiam outros têlo feito melhor, mais brilhante, mais ornado. Ninguém entretanto, com mais entusiasmo, com mais coração, com mais sinceridade e, portanto, com o mesmo ímpeto, a mesma coragem... (p. xxix)

Tal disposição já aparece inscrita na epígrafe do livro, que diz o seguinte: "Se outros per ventuira em esta cronica buscam fremosura e novidade de pallavras, e nom a çertidom das estorias, desprazer lhe há de nosso rrazoado, muito ligeiro a elles douvir e nom sem gram trabalho a nos de hordenar. (p. xiii)" 
O fato de essas palavras terem sido escritas por Fernão Lopes, um português, não reduz a contundência do relato, antes sublinha a decadência de um povo que teve grandes homens como o cronista e acabou reduzido a um bando de quitandeiros fazendo dinheiro no Brasil à custa do furto nos negócios e da avareza.

A pergunta que pode ficar é a seguinte: por que diabos constitui coragem assim tão notável escrever mal de portugueses? Porque, para Antônio Torres, a imprensa nacional sofre de verdadeiro pavor do português. Assim enriquecido, além de pagar anúncios aos jornais constitui uma espécie de elite influente que, através de seu dinheiro mal ganho, entrincheira-se na Associação Comercial e em outros redutos de prestígio e de poder. Como o brasileiro médio buscaria instrução somente nos jornais, já que pouco lê livros, o que temos é todo um povo subjugado diante desse mito criado pelo jornalismo covarde e antinacionalista.

O preâmbulo, no entanto, embora interessante como demonstração do estado de espírito de um tempo, só ganha importância quando retoma elementos das observações feitas acerca da Inconfidência na conferência propriamente dita. Não é coincidência que a resposta de Vitório de Castro vá se ater a ele em grande parte, preocupando-se em rebater as "terríveis" acusações contra os portugueses. Para rebater Antônio Torres, ele também acaba caindo no ridículo. Discutir o valor do soldado português na Primeira Guerra, transcrevendo, no original e em tradução, uma carta de um militar alemão de alta patente que ressalta as qualidades de seus então inimigos portugueses é somente um exemplo dessa postura.

O mais importante, no entanto, na resposta de Castro, é sua recusa ao tipo de nacionalismo reacionário de As razões da Inconfidência, alertando mesmo para as conseqüências futuras do apoio a essa casta de idéias: "O Brasil não pode estar por mais tempo na ilusão de que o movimento jacobino é um movimento de refluxo histórico e mais nada." ${ }^{2}$ Se o nacionalismo era moda nos anos 20, não era uma moda única. Basta pensarmos que o mesmo impulso de compreender e valorizar o país gerou diferentes atitudes estéticas no interior do grupo modernista de São Paulo, que vão desde o interesse pela cultura popular de Mário de Andrade até a xenofobia do grupo da Anta. E é exatamente esse tipo de pensamento reacionário, alimentado por diferentes intelectuais, de Jackson de

2 CASTRO, V. de. Brasileiros e portugueses. Rio de Janeiro: Teixeira \& Cia., 1925. p. 6. Daqui para a frente aparecerá apenas, entre parênteses, a página desta edição de onde forem tiradas as citações. 
Figueiredo a Plínio Salgado, que acabaria desembocando, já na década seguinte, em um movimento como o integralismo.

Infelizmente, Vitório de Castro falha no mais importante. Ao invés de discutir o que é central na visão de seu oponente, perde-se em considerações pequenas e mais que questionáveis. É assim que ele vai fazer um estranho cálculo para provar que as centenas de arrobas de ouro e a enormidade de diamante que saiu de Minas em direção a Portugal no século XVIII não chegaria, em valores corrigidos, a cinco milhões de dólares. ${ }^{3}$ É também assim que ele vai transcrever a execução de Maria Antonieta, para que o leitor possa ver que os portugueses foram até piedosos com os inconfidentes - embora admita que, antes da Inconfidência, tenha sido cruel o suplício de Felipe dos Santos, atado a um cavalo e arrastado pelas ruas de Vila Rica até a morte.

Principalmente, ele se torna tão implicante quanto Alberto Torres quando decide dedicar todo um capítulo à escravidão, esforçando-se por mostrar que ela não era exceção na Europa, não causando repugnância às nações civilizadas, e que, portanto, os portugueses estariam plenamente justificados por cometerem o que ele próprio chama de "crime inaudito". O problema é que a escravidão não é discutida em As razões da Inconfidência, como o próprio Castro tem que admitir:

Embora sem se manifestar claramente et pour cause, por todas as páginas de As razões da Inconfidência há, diluída, uma acusação tremenda contra os portugueses: a de haverem colonizado o Brasil com negros trazidos em ferro do continente africano e a de os terem conservado como escravos, o que representaria um crime hediondo. (p. 43)

Como se vê, ao fim e ao cabo, esta polêmica é um caso clássico de roto falando do esfarrapado. Mas é exatamente por isso que ela pode ser significativa para quem esteja querendo entender como a visão a respeito das relações entre Brasil e Portugal, a partir de certos elementos, foi se recolocando e se transformando até que intelectuais de maior porte pudessem, nos anos seguintes,

3 Ver o capítulo "A rapina lusitana", p. 75-85. 
estabelecer as grandes sínteses que até hoje nos ocupam, como é o caso de Casa Grande e Senzala e Raizes do Brasil.

É assim que Antônio Torres, no afã de demonstrar a vileza do caráter português, vai em busca da repressora legislação que regulou a região das Minas nos século XVIII. Sua principal fonte primária são as ordem régias expedidas ao tempo. O historiador português que ele evoca é Oliveira Martins, sempre pronto a apontar os defeitos do velho Portugal. Uma de suas fontes secundárias centrais tem como tema a região dos diamantes, onde as proibições foram ainda mais rigorosas que em Vila Rica - trata-se do hoje clássico trabalho de Joaquim Felício dos Santos, Memórias do distrito Diamantino, que, tendo sido escrito na década de 1860, foi publicado em livro apenas em 1924, pela mesma editora que imprimiria As razões da Inconfidência ${ }^{4}$

Quando busca as razões dessa legislação draconiana - no fundo as tais razões da Inconfidência - Antônio Torres encontra o traço do caráter português que mais o interessará: a cobiça. Era preciso extrair o ouro - daí a proibição a todas as atividades que não fossem a mineração, ou seja, a indústria têxtil, a tipografia, a instrução pública. Era preciso não deixar escapar um centavo - daí a excessiva taxação, a punição exemplar de quem burlasse o físco. É claro que à cobiça se uniria a incapacidade de organização e de administração que teria feito todo o ouro brasileiro escoar para a Inglaterra.

No entanto, a seguinte passagem não é de Antônio Torres:

Nunca soubera transformar em gozo a riqueza conquistada. A sua energia intensiva e extensiva concentrava-se num sonho de enriquecimento que durou séculos, mas sempre enganador e fugidio. Com essa ilusão vinha morrer, sofrendo da mesma fome, da mesma sede, da mesma loucura. Ouro. Ouro. Ouro.

Cobiça. ${ }^{5}$

4 Ver: SANTOS, J. F. Memórias do distrito Diamantino da comarca do Serro Frio (Província de Minas Gerais). Rio de Janeiro: Castilho, 1924.

5 PRADO, P. Retrato do Brasil. 8. ed. São Paulo: Cia. das Letras, 1997. p. 129. Daqui para a frente aparecerá apenas, entre parênteses, a página desta edição de onde forem tiradas as citações. 
É de Paulo Prado, em Retrato do Brasil, um estudo que está longe da pura acusação, movido que é pelo interesse de investigar quem somos. Pois foi esse homem de negócios e intelectual, cosmopolita e amigo dos portugueses, que elegeu a cobiça como um dos eixos da colonização portuguesa que marcaram nossa constituição como nação. Um outro eixo é a luxúria, também apontada de passagem por Antônio Torres:

Não sei se Freud já terá ido a Portugal. É possível que não. Entretanto creio que Portugal seria para esse famoso professor um vasto campo de observação. Se, de acordo com certas teorias, todas as ações e volições do homem estão submetidas ao instinto sexual, entre os portugueses esse instinto predomina e prevalece de um modo tirânico. Deve nascer daí a curteza e, em certos casos, a absoluta falta de inteligência que caracteriza esse povo, assim como estes milhões de desgraçados brasileiros que dele descendem. (p. civ)

Vale a pena dizer, antes de voltarmos a Paulo Prado, que a resposta de Vitório de Castro a essas afirmações de Torres é o ponto alto de Brasileiros e portugueses. Além de dar uma rápida lição sobre Freud, ele aproveita para fazer uma análise do "caso Antônio Torres", diagnosticando um "trauma psíquico" (p. 103) que causaria uma ligação inabalável com o passado, que o fazia ficar "grudado ao cadafalso do alferes Xavier" (p. 104).

Paulo Prado, ao contrário de Antônio Torres, não vê a sexualidade como tara, antes a enxerga como um dos fatores de nossa formação: "Do contato dessa sensualidade com o desregramento e a dissolução do conquistador europeu surgiram as nossas primeiras populações mestiças" (p. 76).

Note-se que, publicado apenas três anos depois de As razões da Inconfidência, Retrato do Brasil opera com termos familiares àqueles leitores que acompanharam a polêmica de 1925 - termos que designam condutas reprováveis. O sentido, no entanto, que eles recebem nesse novo livro, é como que uma preparação para o que fariam Gilberto Freyre e Sérgio Buarque de Holanda.

A luxúria, em Casa Grande e Senzala, converte-se no meio por excelência de aproximação do colonizador com o colonizado, índice da abertura desse colonizador, de sua capacidade de aceitar o que lhe é diferente e com ele interagir. 
Aquilo que era chamado de cobiça aparece para Gilberto Freyre como espírito de aventura, e o aventureiro deixa de ser aquele elemento disposto a todos os crimes para ter o que deseja e passa a ser o que, em sua disponibilidade de quem não tem lar fixo, é capaz de criar toda uma nova civilização tropical.

É esse mesmo espírito aventureiro que, em contraposição ao comportamento do espanhol, que lhe parece um sistemático ladrilhador, Sérgio Buarque de Holanda reconhecerá o semeador. Ainda que com uma indisfarçada nostalgia da ordem de quem ladrilha, Raizes do Brasil estabelece de vez uma nova leitura do desregramento português - afinal, semear é também fazer nascer, construir algo.

Por mais irracionais que possam nos parecer, vistos de hoje, um tamancófilo que reduz Tiradentes a um louco de quem Portugal nos salvou, ou um tamancófobo que, ao contrário, vê na execução de Tiradentes a vitória definitiva do espírito brasileiro sobre o português, retomar suas irracionalidades pode revelar muita coisa. Pode, por um lado, ajudar a identificar os insuspeitados antecedentes do melhor pensamento brasileiro do século XX. E pode também dar boas pistas de por que a cultura brasileira deliberadamente se afastou tanto de Portugal no século XX.

\section{RESUMO}

As Razões da Inconfidência (1925), livro de Antônio Torres, obteve, de um lado, grande sucesso, e, de outro, provocou fortes reações. A mais forte foi a do jornalista Vitório de Castro, com o livro Brasileiros e portugueses. Mais do que a Inconfidência Mineira, foi o forte sentimento antiportuguês do livro de Torres o motivador de sua repercussão. A recuperação dessa polêmica nos dá imagem privilegiada das relações Brasil-Portugal nos anos que sucederam a comemoração do centenário da Independência. Palavras-chave: Relações luso-brasileiras, Inconfidência Mineira, ensaio brasileiro. 


\begin{abstract}
Antônio Torres's book, As razões da Inconfidência (1925) obtained a great success, becoming an instant best-seller, but, at the same time, it had to face a large opposition. The cause of these antagonic reactions was less the historic vision of the Inconfidencia Mineira the book presented than its strong anti-portuguese content. The polemic aroused by As razões da Inconfidência shows how complex was the Portugal's image in Brazil in the years around the Centenary of the Independence comemorations.

Key-words: Brazil-Portugal relations, Inconfidência Mineira, brazilian essay.
\end{abstract}

\title{
REFERÊNCIAS
}

CASTRO, V. de. Brasileiros e portugueses. Rio de Janeiro: Teixeira \& Cia., 1925.

PRADO, P. Retrato do Brasil. 8. ed. São Paulo: Cia. das Letras, 1997.

SANTOS, J. F. Memórias do distrito Diamantino da comarca do Serro Frio (Província de Minas Gerais). Rio de Janeiro: Castilho, 1924.

TORRES, A. As razões da Inconfidência. 3. ed. Rio de Janeiro: Castilho, 1925. 